\title{
The impact of manganese substitution on the structure and properties of tetrahedrite
}

Article

Accepted Version

Guélou, G., Powell, A., Smith, R. I. and Vaqueiro, P. (2019)

The impact of manganese substitution on the structure and properties of tetrahedrite. Journal of Applied Physics, 126 (4). 031928JAP. ISSN 0021-8979 doi: https://doi.org/10.1063/1.5110696 Available at https://centaur.reading.ac.uk/84795/

It is advisable to refer to the publisher's version if you intend to cite from the work. See Guidance on citing.

To link to this article DOI: http://dx.doi.org/10.1063/1.5110696

Publisher: American Institue of Physics

All outputs in CentAUR are protected by Intellectual Property Rights law, including copyright law. Copyright and IPR is retained by the creators or other copyright holders. Terms and conditions for use of this material are defined in the End User Agreement.

\section{www.reading.ac.uk/centaur}

\section{CentAUR}

Central Archive at the University of Reading 
Reading's research outputs online 


\section{THE IMPACT OF MANGANESE SUBSTITUTION ON THE STRUCTURE AND PROPERTIES OF TETRAHEDRITE}

Gabin P. L. Guélou, ${ }^{\mathrm{a}}{ }^{\dagger}$ Anthony V. Powell, ${ }^{\mathrm{a}}$ Ronald I. Smith ${ }^{\mathrm{b}}$ and Paz Vaqueiro ${ }^{\mathrm{a} *}$

a Department of Chemistry, University of Reading, Whiteknights, Reading RG6 6AD, England, United Kingdom

${ }^{\mathrm{b}}$ STFC, Rutherford Appleton Laboratory, ISIS Facility, Didcot OX11 0QX, United Kingdom

*Corresponding author

E-mail: p.vaqueiro@reading.ac.uk

† Current address: CRISMAT, CNRS, Normandie University, ENSICAEN, UNICAEN, 14000 Caen, France 


\begin{abstract}
The crystal structure of the tetrahedrites $\mathrm{Cu}_{12-\mathrm{x}} \mathrm{Mn}_{\mathrm{x}} \mathrm{Sb}_{4} \mathrm{~S}_{13}(\mathrm{x}=0,1)$ has been studied by powder neutron diffraction between room temperature and $773 \mathrm{~K}$. At all temperatures investigated, manganese exclusively occupies tetrahedral sites, while the trigonal-planar sites contain only copper. In situ diffraction data confirm the stability of the tetrahedrite phase up to $773 \mathrm{~K}$, with no evidence of copper mobility at elevated temperatures. Analysis of atomic displacement parameters indicate that there are low-energy vibrations associated with the trigonal-planar and the tetrahedral copper cations. The Einstein temperatures for the copper cations range between 79 and $91 \mathrm{~K}$. Manganese substitution increases the electrical resistivity and the Seebeck coefficient, while the thermal conductivity is reduced. This results in a modest improvement in the thermoelectric figure of merit for $\mathrm{Cu}_{12} \mathrm{MnSb}_{4} \mathrm{~S}_{13}$, which reaches $\mathrm{ZT}=0.56$ at $573 \mathrm{~K}$.
\end{abstract}




\section{INTRODUCTION}

Concerns about increasing atmospheric $\mathrm{CO}_{2}$ levels and climate change are driving research into alternative energy generation and conversion technologies. Thermoelectric power generation, which entails conversion of heat into electrical power, could improve energy efficiency through the recovery of waste heat. Large-scale deployment of thermoelectric power generation requires the discovery of sustainable and environmentally-friendly materials, given that current generation of commercial thermoelectric materials contain toxic and scarce elements such as tellurium. The efficiency with which heat is converted into electrical power is related to a figure of merit, $\mathrm{ZT}=\mathrm{S}^{2} \mathrm{~T} / \mathrm{\rho}$, which depends on the Seebeck coefficient (S), electrical resistivity $(\rho)$ and thermal conductivity $(\kappa)$ of the thermoelectric materials used.

Tetrahedrites, which are currently attracting considerable interest as thermoelectric materials, are minerals formulated as $\mathrm{A}_{10} \mathrm{~B}_{2} \mathrm{C}_{4} \mathrm{Q}_{13}(\mathrm{~A}=\mathrm{Cu}, \mathrm{Ag} ; \mathrm{B}=\mathrm{Mn}, \mathrm{Fe}, \mathrm{Co}, \mathrm{Ni}, \mathrm{Zn}, \mathrm{Cu}, \mathrm{Hg}, \mathrm{Cd} ; \mathrm{C}$ $=\mathrm{As}, \mathrm{Sb}, \mathrm{Bi} ; \mathrm{Q}=\mathrm{S}, \mathrm{Se}){ }^{1}$ The complex structure of tetrahedrite (space group $I \overline{4} 3 m$ ) is often described as a defect sphalerite derivative, with three distinct cation sites. The transitionmetal cations, $\mathrm{A}$ and $\mathrm{B}$, reside in $12 d$ tetrahedral sites and $12 e$ trigonal planar sites, while the pnictogen cations, C, are located in trigonal pyramidal sites (Figure 1). Alternatively, the tetrahedrite structure can be depicted as a collapsed sodalite framework. ${ }^{2}$ Although the minerals of the tetrahedrite family have been known for several decades, ${ }^{3}$ their potential as thermoelectric materials was only reported recently, following the publication in 2012 of the thermoelectric properties of substituted tetrahedrites, $\mathrm{Cu}_{10} \mathrm{TM}_{2} \mathrm{Sb}_{4} \mathrm{~S}_{13}(\mathrm{TM}=\mathrm{Mn}, \mathrm{Fe}, \mathrm{Co}, \mathrm{Ni}$, $\mathrm{Cu}, \mathrm{Zn}) .{ }^{4}$ The literature on thermoelectric tetrahedrites has been reviewed by Chetty et al. ${ }^{5}$ Examples of promising materials include zinc-substituted tetrahedrite with ZT close to unity at $723 \mathrm{~K},{ }^{6}$ cobalt-substituted tetrahedrite with $\mathrm{ZT}=0.98$ at $673 \mathrm{~K},{ }^{7}$ or the doubly substituted tetrahedrite $\mathrm{Cu}_{10.5} \mathrm{NiZn}_{0.5} \mathrm{Sb}_{4} \mathrm{~S}_{13}$, which reaches $\mathrm{ZT}>1$ at $723 \mathrm{~K} .{ }^{8}$ Heo et al. reported that 
manganese substitution results in an impressive thermoelectric performance, with $\mathrm{Cu}_{11} \mathrm{MnSb}_{4} \mathrm{~S}_{13}$ reaching $\mathrm{ZT}=1.13$ at only $575 \mathrm{~K} ;{ }^{9}$ however, this contrasts with the reduction in thermoelectric performance with manganese substitution observed by Chetty et al. ${ }^{10}$ The substitution of $\mathrm{Sb}$ by $\mathrm{Te}$ has been investigated, and leads to $\mathrm{ZT}=0.92$ at $723 \mathrm{~K}$ for $\mathrm{Cu}_{12} \mathrm{Sb}_{3} \mathrm{TeS}_{13} .{ }^{11}$ Natural tetrahedrites have also been studied, with mixtures of mineral $\mathrm{Cu}_{12}$ ${ }_{x}(\mathrm{Zn}, \mathrm{Fe})_{\mathrm{x}}(\mathrm{Sb}, \mathrm{As})_{4} \mathrm{~S}_{13}(\mathrm{x} \leq 2)$ and synthetic $\mathrm{Cu}_{12} \mathrm{Sb}_{4} \mathrm{~S}_{13}$ achieving $\mathrm{ZT}>0.8$ above $600 \mathrm{~K} .{ }^{12,13}$

In the case of partially-substituted tetrahedrites $\mathrm{Cu}_{12-\mathrm{x}} \mathrm{TM}_{\mathrm{x}} \mathrm{Sb}_{4} \mathrm{~S}_{13}$, X-ray diffraction does not enable unequivocal determination of the distribution of copper and the transition-metal cation over the $12 d$ tetrahedral and $12 e$ trigonal planar sites. However neutron diffraction has established that iron and nickel preferentially occupy tetrahedral sites. ${ }^{14,15}$ Here, we seek to exploit the excellent contrast between manganese and copper afforded by neutron scattering to investigate the impact of manganese substitution on the copper sublattice. Given the contradictory reports on the thermoelectric performance of manganese-containing tetrahedrites, ${ }^{9,10}$ we also present the results of thermoelectric property measurements of these materials.

\section{EXPERIMENTAL DETAILS}

\section{Synthesis}

Mixtures of the elements S (Sigma Aldrich, flakes, $99.99 \%$ ), Sb (Alfa Aesar, $99.5 \%$ ), Cu (Sigma Aldrich, $99.5 \%$ ) and Mn (Alfa Aesar, $99.95 \%$ ), with the overall composition $\mathrm{Cu}_{12-}$ ${ }_{x} \mathrm{Mn}_{\mathrm{x}} \mathrm{Sb}_{4} \mathrm{~S}_{13}$ ( $\mathrm{x}=0$ and 1), were milled using a Retsch Planetary Ball Mill PM100. The stainless-steel jar was loaded under an Ar atmosphere, and samples were milled at $600 \mathrm{rpm}$ for 480 minutes. The ratio of powdered sample to balls was 3:10 (in weight). The ball-milled tetrahedrites were then sealed in evacuated silica tubes and heated in a furnace. The optimal heat-treatment conditions to obtain good-quality samples are as follow: The unsubstituted 
tetrahedrite was heated with a ramp of $1 \mathrm{~K} \mathrm{~min}^{-1}$ to $773 \mathrm{~K}$, held at this temperature for $64 \mathrm{~h}$, and then cooled rapidly. The $\mathrm{Cu}_{11} \mathrm{MnSb}_{4} \mathrm{~S}_{13}$ sample, however, required a multi-stage heating/cooling process. Initially, it was heated at $973 \mathrm{~K}$ for $3 \mathrm{~h}$, after which it was held at $823 \mathrm{~K}$ for $30 \mathrm{~h}$, prior to cooling to room temperature at the natural cooling rate of the furnace. It was then reground and underwent a second heat treatment at $823 \mathrm{~K}$ for $30 \mathrm{~h}$.

\section{Powder X-ray diffraction}

For initial sample characterisation, powder X-ray diffraction data were collected over the angular range $5 \leq 2 \theta /^{\circ} \leq 85$, on a Bruker D8 Advance powder diffractometer, using $\mathrm{Cu} \mathrm{K}_{\alpha 1}$ radiation $(\lambda=1.54046 \AA)$.

\section{Powder neutron diffraction}

Time-of-flight powder neutron diffraction data were collected, as a function of temperature, on the Polaris diffractometer ${ }^{16}$ at the ISIS facility. Samples, sealed under vacuum in low boron content silica tubes, were inserted into cylindrical vanadium sample containers and loaded into a furnace on the diffractometer. Diffraction data for $\mathrm{Cu}_{12} \mathrm{Sb}_{4} \mathrm{~S}_{13}$ were collected on heating and cooling over the temperature range $303 \leq \mathrm{T} / \mathrm{K} \leq 773$, while for $\mathrm{Cu}_{11} \mathrm{MnSb}_{4} \mathrm{~S}_{13}$ data were only collected on heating. ${ }^{17}$ The instrumental and sample environment background was measured by loading an empty silica ampoule into the furnace. Data reduction, which included subtraction of a furnace and empty silica ampoule dataset, was performed using the Mantid software. ${ }^{18}$ Rietveld refinements were carried out using the GSAS software, ${ }^{19}$ and incorporating data from detector banks 5,4 and 3 (average $2 \theta=146.72^{\circ}, 92.59^{\circ}$ and $52.21^{\circ}$ respectively). The structural model initially used in the Rietveld refinements was derived from that obtained using single crystal $\mathrm{X}$-ray diffraction data for $\mathrm{Cu}_{12-\mathrm{x}} \mathrm{Mn}_{\mathrm{x}} \mathrm{Sb}_{4} \mathrm{~S}_{13}{ }^{10}$ Isotropic thermal displacement parameters were used for tetrahedral $\mathrm{Cu}(1), \mathrm{Sb}, \mathrm{S}(1), \mathrm{S}(2)$, while the trigonal planar $\mathrm{Cu}(2)$ was modelled using anisotropic thermal displacement parameters. A 
second phase, corresponding to the impurity $\mathrm{Cu}_{3} \mathrm{SbS}_{4},{ }^{20}$ was also introduced into the Rietveld refinements.

The thermal expansion coefficient was calculated as:

$$
\alpha=\frac{\left(a_{T 2}-a_{T 1}\right) / a_{T 1}}{\Delta T}
$$

where $a_{T 1}$ and $a_{T 2}$ correspond to the lattice parameter at temperatures $T_{1}$ and $T_{2}$ respectively, and $\Delta T$ is the temperature difference, $T_{2}-T_{1}$.

\section{Thermoelectric properties}

Measurements of the electrical properties were carried out on consolidated ingots with densities greater than $95 \%$ of the crystallographic density. Powders were hot pressed for 30 minutes at $80 \mathrm{MPa}$ and $723 \mathrm{~K}$, under a flowing nitrogen atmosphere. The density of each consolidated ingot was measured by the Archimedes method. Measurements of electrical resistivity and Seebeck coefficient over the temperature range $303 \leq \mathrm{T} / \mathrm{K} \leq 573$ were performed using a Linseis LSR-3 instrument, under a He atmosphere.

The thermal diffusivity over the temperature range $303 \leq \mathrm{T} / \mathrm{K} \leq 573$ was determined using a Netzsch LFA 447 NanoFlash instrument. The Dulong-Petit law was used to calculate specific heat values of $0.434 \mathrm{~J} \mathrm{~K}^{-1} \mathrm{~g}^{-1}$ for $\mathrm{Cu}_{12} \mathrm{Sb}_{4} \mathrm{~S}_{13}$ and $0.436 \mathrm{~J} \mathrm{~K}^{-1} \mathrm{~g}^{-1}$ for $\mathrm{Cu}_{11} \mathrm{MnSb}_{4} \mathrm{~S}_{13}$. The electronic thermal conductivity was estimated using the Wiedemann-Franz law, $\kappa_{\mathrm{el}}=L \sigma \mathrm{T}$. The Lorenz number, $L$, was estimated using $L=1.5+\exp (-|S| / 116)$, where $L$ is in units of $10^{-8} \mathrm{~W} \Omega \mathrm{K}^{-2}$ and $\mathrm{S}$ in $\mu \mathrm{V} \mathrm{K}^{-1} .^{21}$

The uncertainty in the measurements of Seebeck coefficient, electrical resistivity, and thermal conductivity can be estimated to be $\approx 5 \%$. Discrepancies in ZT values between different laboratories have been estimated to range between 11 and $16 \% .^{22}$ 


\section{RESULTS AND DISCUSSION}

Analysis of powder X-ray diffraction data indicates that samples consist primarily of a tetrahedrite phase, although a small amount of $\mathrm{Cu}_{3} \mathrm{SbS}_{4}$ is also present, the amount of which decreases from $\mathrm{Cu}_{12} \mathrm{Sb}_{4} \mathrm{~S}_{13}$ (8 wt $\%$ ) to $\mathrm{Cu}_{11} \mathrm{MnSb}_{4} \mathrm{~S}_{13}$ (3 wt $\%$ ). The refined unit cell parameters determined using X-ray diffraction (Supplementary Information), which are $a=$ 10.3234(2) $\AA$ and $a=10.3865(3) \AA$ for $\mathrm{Cu}_{12} \mathrm{Sb}_{4} \mathrm{~S}_{13}$ and $\mathrm{Cu}_{11} \mathrm{MnSb}_{4} \mathrm{~S}_{13}$ respectively, and the presence of a $\mathrm{Cu}_{3} \mathrm{SbS}_{4}$ impurity phase, are in agreement with the results presented by Chetty et $a l .{ }^{10}$ In preliminary Rietveld refinements using X-ray diffraction data, manganese was placed on the tetrahedral site, but due to the similarity in the X-ray scattering powers of manganese and copper no definitive conclusion on its location on the structure could be drawn. For this reason, powder neutron diffraction data were collected and analysed. The markedly dissimilar coherent neutron scattering length of copper $(b=7.718 \mathrm{fm})$ and manganese $(b=-3.73 \mathrm{fm})$ enabled us to establish unambiguously the location of each transition-metal cation. When manganese is placed on the trigonal planar site, clear mismatches between the experimental and calculated intensities are observed, while the agreement improves significantly when manganese is placed exclusively on the tetrahedral site. Therefore, the excellent contrast provided by neutron diffraction strongly supports manganese substitution on the tetrahedral $(12 d)$ rather than the trigonal planar (12e) site. This is consistent with the results of previous neutron diffraction experiments on iron and nickelsubstituted tetrahedrites, ${ }^{14,15}$ which although showing less contrast between cations $(\mathrm{b}(\mathrm{Fe})=$ $9.45 \mathrm{fm}, \mathrm{b}(\mathrm{Ni})=10.3 \mathrm{fm})$, led to the conclusion that divalent transition metal cations occupy the tetrahedral site. The final Rietveld refinements using neutron data collected at room temperature for $\mathrm{Cu}_{12-\mathrm{x}} \mathrm{Mn}_{\mathrm{x}} \mathrm{Sb}_{4} \mathrm{~S}_{13}(\mathrm{x}=0,1)$ are given in Figures 2 and 3 respectively, while the refined parameters as a function of temperature can be found in the Supplementary 
Information. The quality of the refinements was excellent in all instances, with $\mathrm{R}_{\mathrm{wp}}$ values between $2 \%$ and $3 \%$.

Analysis of our temperature-dependent diffraction data indicates that when samples are contained in evacuated and sealed ampoules, the tetrahedrite phase is retained up to the maximum temperature investigated $(773 \mathrm{~K})$, with no evidence of decomposition, as sulfur loss is avoided. This contrasts with the behaviour found when $\mathrm{Cu}_{12} \mathrm{Sb}_{4} \mathrm{~S}_{13}$ is heated under a flowing $\mathrm{N}_{2}$ atmosphere, which leads to a complex decomposition into $\mathrm{Cu}_{3} \mathrm{SbS}_{3}$ from $673 \mathrm{~K}$ up to $753 \mathrm{~K}$ due to sulfur volatilisation. ${ }^{15}$ Heating of $\mathrm{Cu}_{12} \mathrm{Sb}_{4} \mathrm{~S}_{13}$ under dynamic vacuum also results in decomposition due to sulfur loss. ${ }^{23}$ The substitution of $\mathrm{Cu}^{+}(\mathrm{r}=0.60 \AA)$ by $\mathrm{Mn}^{2+}$, which has a larger ionic radius $(r=0.66 \AA)$, results in an expansion of the unit cell with manganese substitution (Supplementary Information). Although the lattice parameter for $\mathrm{Cu}_{11} \mathrm{MnSb}_{4} \mathrm{~S}_{13}$ increases linearly over the whole temperature range, data for $\mathrm{Cu}_{12} \mathrm{Sb}_{4} \mathrm{~S}_{13}$ show a slight anomaly in the slope at approximately $400 \mathrm{~K}$ (Supplementary Information). Taking this into account, the thermal expansion coefficient was determined between $303 \leq \mathrm{T} / \mathrm{K} \leq$ 773 for the manganese-substituted sample, and above $400 \mathrm{~K}$ for $\mathrm{Cu}_{12} \mathrm{Sb}_{4} \mathrm{~S}_{13}$. With manganese substitution, the thermal expansion coefficient decreases from the value of $2.37(4) \times 10^{-5} \mathrm{~K}^{-1}$ found for the unsubstituted tetrahedrite to $1.35(3) \times 10^{-5} \mathrm{~K}^{-1}$. A similar trend has been found for iron substituted tetrahedrites: the thermal expansion coefficient decreases with increasing iron substitution. ${ }^{24}$

Rietveld refinements reveal a large anisotropic atomic displacement parameter for the trigonal planar $\mathrm{Cu}(2)$ cation in the direction out of the plane formed by two $\mathrm{S}(1)$ anions and one $\mathrm{S}(2)$ anion (Figure 4(a)), and pointing towards two Sb cations. At room temperature, the atomic displacement parameters for the copper cations, particularly $\mathrm{Cu}(2)$, are larger than those for sulfur and antimony (Supplementary Information). They also exhibit a stronger temperature dependence (Figure 4(b)). The Debye temperature can be estimated from the 
slope of a plot of the weighted average $\mathrm{U}_{\text {iso }}$ for the framework atoms ( $\mathrm{Sb}$ and $\mathrm{S}$ ) vs. temperature. ${ }^{25}$ This results in a Debye temperature of $257 \mathrm{~K}$, comparable to the values of 239 $\mathrm{K}$, obtained using low-temperature diffraction data, ${ }^{26} 244 \mathrm{~K}$, extracted from elastic measurements, ${ }^{10}$ and $281 \mathrm{~K}$, determined from first-principle calculations. ${ }^{27}$ The Einstein temperatures for the copper cations can be estimated from a plot of $\mathrm{U}_{\text {isoleq }}$ vs. temperature. ${ }^{25}$ This results in values of 79 and $82 \mathrm{~K}$ for $\mathrm{Cu}(2)$, and 88 and $91 \mathrm{~K}$ for $\mathrm{Cu}(1)$ in $\mathrm{Cu}_{12} \mathrm{Sb}_{4} \mathrm{~S}_{13}$ and $\mathrm{Cu}_{11} \mathrm{MnSb}_{4} \mathrm{~S}_{13}$ respectively, which would correspond to energies ranging between 6.8 and 7.8 meV. These values are very similar to those found for $\mathrm{Cu}(1)$ and $\mathrm{Cu}(2)$ in copper-rich tetrahedrites ${ }^{28}$ as well as to the Einstein temperature of $72 \mathrm{~K}$ determined for $\mathrm{Cu}(2)$ using lowtemperature synchrotron diffraction data. ${ }^{26}$ Tetrahedrally-coordinated copper in the oxychalcogenides BiOCuQ also exhibits a low-energy vibrational mode, evidenced by the behaviour of the atomic thermal parameter, which is similar to that found here for $\mathrm{Cu}(1)$, and the copper vibrational density of states. ${ }^{29}$ The nature of the bonding and the rattling behaviour of the trigonal planar $\mathrm{Cu}(2)$ cations in tetrahedrite have been investigated by Lai et al.,${ }^{30}$ who found that $\mathrm{Cu}(2)$ forms covalent bonds with $\mathrm{S}(1)$ and $\mathrm{S}(2)$, and exhibits an additional weak bonding fluctuation with two $\mathrm{Sb}$ cations (bond order $\approx 0.10$ ). This means that rather than trigonal planar $\mathrm{Cu}(2) \mathrm{S}_{3}$ units, the structural units are effectively $\mathrm{Sb}[\mathrm{CuS} 3] \mathrm{Sb}$ trigonal bypyramids. A low-energy vibrational mode at $\sim 3 \mathrm{meV}$, determined by inelastic neutron scattering, has been attributed to the rattling of the $\mathrm{Cu}(2)$ atom within this trigonal bypyramid. ${ }^{31}$ First-principle calculations predict two vibrational peaks between 3 and $5 \mathrm{meV}$ for $\mathrm{Cu}(2)$, with the partial vibrational density of states for $\mathrm{Cu}(1)$ showing a peak at higher energies, close to $10 \mathrm{meV}^{27}$ The absence of the low-energy $\mathrm{Cu}(2)$ vibrational mode in inelastic neutron scattering measurements of the tetrahedrite-related phase $\mathrm{Cu}_{10} \mathrm{Te}_{4} \mathrm{~S}_{13}$ (although it is present in $\mathrm{Cu}_{12} \mathrm{Sb}_{2} \mathrm{Te}_{2} \mathrm{~S}_{13}$ ) confirms the importance of $\mathrm{Sb}$ bonding for the rattling vibration of $\mathrm{Cu}(2){ }^{32}$ 
It has been previously shown that for copper-rich tetrahedrites, $\mathrm{Cu}_{12+\mathrm{x}} \mathrm{Sb}_{4} \mathrm{~S}_{13}(0<\mathrm{x} \leq 2.0)$, the copper cations become mobile above $393 \mathrm{~K},{ }^{28}$ resulting in remarkably low thermal conductivities. Structural evidence for copper ion mobility can be found in the site occupancy factors of the copper cations, which decrease with rising temperature above the onset of copper ionic mobility. For the tetrahedrites $\mathrm{Cu}_{11} \mathrm{MnSb}_{4} \mathrm{~S}_{13}$ and $\mathrm{Cu}_{12} \mathrm{Sb}_{4} \mathrm{~S}_{13}$ investigated here, attempts to refine the copper site occupancy factors in Rietveld refinements using data collected at high temperatures result in values very close to unity. This suggests that copper ionic mobility is restricted to copper-rich phases, and that stoichiometric tetrahedrites should not suffer from the serious degradation issues that affect superionic conductors. ${ }^{33}$ In the copper-rich tetrahedrites $\mathrm{Cu}_{12+\mathrm{x}} \mathrm{Sb}_{4} \mathrm{~S}_{13},{ }^{29}$ the unit cell volume expands to accommodate the additional copper, and this expansion may facilitate a diffusion pathway for the mobile copper ions.

Figure 5 shows the electrical resistivity, Seebeck coefficient, and power factor $\left(S^{2} \rho^{-1}\right)$ for $\mathrm{Cu}_{12-\mathrm{x}} \mathrm{Mn}_{\mathrm{x}} \mathrm{Sb}_{4} \mathrm{~S}_{13}$ ( $\mathrm{x}=0$ and 1), as a function of temperature. $\mathrm{Cu}_{12} \mathrm{Sb}_{4} \mathrm{~S}_{13}$ is a $p$-type semiconductor with a reasonably low electrical resistivity, in agreement with previous reports of the electrical transport properties of this material. ${ }^{6,9,10,26}$ Substitution of copper by manganese at the tetrahedral site increases both the electrical resistivity and the Seebeck coefficient. As discussed by Chetty et al., ${ }^{10}$ this behaviour is consistent with substitution of $\mathrm{Cu}^{+}$by $\mathrm{Mn}^{2+}$, which reduces the hole concentration by introducing electrons in the valence band, thus decreasing the charge carrier concentration. The increase in Seebeck coefficient with manganese incorporation compensates for the increase in electrical resistivity only below $360 \mathrm{~K}$. As a consequence, the highest power factor, $\mathrm{S}^{2} \rho^{-1}=1.08 \mathrm{~mW} \mathrm{~m}^{-1} \mathrm{~K}^{-2}$, is obtained for the unsubstituted tetrahedrite at $590 \mathrm{~K}$. This behaviour is in good agreement with previous reports of the electrical transport properties of manganese-substituted 
tetrahedrites; $;^{9,10}$ the power factor decreases with increasing manganese content, due to the increase in resistivity.

The temperature dependence of the thermal conductivity and the thermoelectric figure of merit for the two tetrahedrites is presented in Figure 6. As discussed earlier, the low thermal conductivity of tetrahedrites is usually attributed to the rattling vibrations of the $\mathrm{Cu}(2)$ cation within the $\mathrm{Sb}\left[\mathrm{CuS}_{3}\right] \mathrm{Sb}$ unit. ${ }^{30,31}$ Substitution with manganese results in a large reduction in thermal conductivity. The almost temperature-independent value of approximately $0.75 \mathrm{~W} \mathrm{~m}^{-}$ ${ }^{1} \mathrm{~K}^{-1}$ found here for $\mathrm{Cu}_{11} \mathrm{MnSb}_{4} \mathrm{~S}_{13}$, corresponds to a reduction of over $40 \%$ with respect to that of the unsubstituted tetrahedrite. The lattice thermal conductivity (Supplementary Information) was estimated by subtracting the calculated electronic contribution from the total thermal conductivity. This confirmed that the reduction in thermal conductivity is due to a decrease in both electronic and lattice contributions, indicating that phonon scattering is increasing as a result of manganese substitution. A reduction in both electronic and lattice thermal conductivity as a result of transition-metal substitution has been found for other partially-substituted tetrahedrites, $\mathrm{Cu}_{12-\mathrm{x}} \mathrm{TM}_{\mathrm{x}} \mathrm{Sb}_{4} \mathrm{~S}_{13} .{ }^{6}$ As mass and volume fluctuations when replacing copper with manganese are relatively small, the increase in phonon scattering might be related to charge-transfer mechanisms, as previously proposed for ternary skutterudites containing elements with similar masses $\left(\mathrm{e}, \mathrm{g}, \mathrm{Ru}_{0.5} \mathrm{Pd}_{0.5} \mathrm{Sb}_{3}, \mathrm{Fe}_{0.5} \mathrm{Ni}_{0.5} \mathrm{Sb}_{3}\right){ }^{34}$ The thermal conductivity reported here is broadly consistent with the results of Chetty et al. ${ }^{10}$ By contrast, Heo et al. found much lower thermal conductivities for manganese substituted samples, $\sim 0.2$ $\mathrm{W} \mathrm{m} \mathrm{m}^{-1} \mathrm{~K}^{-1}$, which are likely to be related to the relatively low density of their samples $(85 \%$ of theoretical value), ${ }^{9}$ as sample porosity is known to have a marked impact on reducing the thermal conductivity. ${ }^{35}$

Owing to the reduction in thermal conductivity with manganese substitution, the figure of merit is improved in the manganese-containing phase, with the highest $\mathrm{ZT}=0.56$ found for 
$\mathrm{Cu}_{11} \mathrm{MnSb}_{4} \mathrm{~S}_{13}$. This value is similar to those for other transition-metal substituted tetrahedrites, $\mathrm{Cu}_{12-\mathrm{x}} \mathrm{TM}_{\mathrm{x}} \mathrm{Sb}_{4} \mathrm{~S}_{13}{ }^{7}$ The significantly higher values of $\mathrm{ZT}$ for manganesesubstituted tetrahedrites reported by Heo et al., who found that $\mathrm{Cu}_{11} \mathrm{MnSb}_{4} \mathrm{~S}_{13}$ reached $\mathrm{ZT}=$ 1.13 at $575 \mathrm{~K},{ }^{9}$ may be related to the low density of their samples.

\section{CONCLUSIONS}

We have shown that in substituted tetrahedrite, manganese cations occupy exclusively the tetrahedral site. Temperature-dependent neutron diffraction data collected up to $773 \mathrm{~K}$ reveal that copper ions remain localised on fully occupied crystallographic sites, in contrast to the behaviour of the copper-rich tetrahedrites, where the onset of copper mobility occurs above $393 \mathrm{~K}^{29}$ Analysis of the atomic displacement parameters leads to the identification of lowenergy phonon modes associated with the trigonal-planar and the tetrahedral copper ions. While it is widely recognised that the low thermal conductivity of tetrahedrites is related to the rattling vibrations of copper ions within the $\mathrm{Sb}\left[\mathrm{CuS}_{3}\right] \mathrm{Sb}$ trigonal bypyramids, ${ }^{6}$ little consideration has been given so far to the contribution of the vibrational modes of the tetrahedral copper ions. Unfortunately, phonon calculations for $\mathrm{Cu}_{12} \mathrm{Sb}_{4} \mathrm{~S}_{13}$ are complicated by the presence of a structural phase transition at approximately $90 \mathrm{~K},{ }^{36}$ and calculations using the room-temperature crystal structure lead to unstable optical phonon branches involving out-of-plane vibrations of the trigonal-planar copper ions, as well as unstable transverse acoustic branches near the $\mathrm{N}$ and $\mathrm{P}$ points. ${ }^{6}$ Elucidation of the low-temperature structure of tetrahedrite, which we will report in due course, is required in order to gain a better understanding of the lattice dynamics in this material.

Thermal conductivity data for $\mathrm{Cu}_{11} \mathrm{MnSb}_{4} \mathrm{~S}_{13}$ reveal that the behaviour of manganesesubstituted tetrahedrites is comparable to that of other transition-metal substituted tetrahedrites. ${ }^{7}$ The much lower thermal conductivities previously reported for manganesesubstituted samples, $\sim 0.2 \mathrm{~W} \mathrm{~m}^{-1} \mathrm{~K}^{-1},{ }^{9}$ are likely to be related to sample porosity. 


\section{Supplementary Information}

See supplementary material for tabulated results of Rietveld refinements, Rietveld refinements using X-ray diffraction data, the temperature dependence of lattice parameters, and the lattice and electronic contribution to the thermal conductivity.

\section{Acknowledgements}

The authors would like to thank the University of Reading for financial support for G.G., and for access to the Chemical Analysis Facility for powder X-ray diffraction. The authors also thank the ISIS Facility and STFC (Science and Technology Facilities Council) for the neutron beam time allocation (RB1510166).

\section{REFERENCES}

1. E. Makovicky, Rev. Mineral. Geochem. 61, 7 (2006).

2. N. E. Johnson, J. R. Craig and J. D. Rimstidt, Am. Mineral. 73, 389 (1988).

3. B. J. Wuensch, Z. Kristallogr. 119, 437 (1964).

4. K. Suekuni, K. Tsuruta, T. Ariga and M. Koyano, Appl. Phys. Express 5, 051201 (2012).

5. R. Chetty, A. Bali and R. C. Mallik, J. Mater. Chem. C 3, 12364 (2015).

6. X. Lu, D. T. Morelli, Y. Xia, F. Zhou, V. Ozolins, H. Chi, X. Y. Zhou and C. Uher, Adv. Energy Mater. 3, 342 (2013).

7. R. Chetty, A. Bali, M. H. Naik, G. Rogl, P. Rogl, M. Jain, S. Suwas and R. C. Mallik, Acta Mater. 100, 266 (2015).

8. X. Li, D. T. Morelli, Y. Xia and V. Ozolins, Chem. Mater. 27, 408 (2015).

9. J. Heo, G. Laurita, S. Muir, M. A. Subramanian and D. A. Keszler, Chem. Mater. 26, 2047 (2014). 
10. R. Chetty, D. S. P. Kumar, G. Rogl, P. Rogl, E. Bauer, H. Michor, S. Suwas, S. Puchegger, G. Giester and R. C. Mallik, Phys. Chem. Chem. Phys. 17, 1716 (2015).

11. X. Lu and D. T. Morelli, J. Electron. Mater. 43, 1983 (2014).

12. X. Lu and D. T. Morelli, MRS Commun. 3, 129 (2013).

13. X. Lu and D. T. Morelli, Phys. Chem. Chem. Phys.15, 5762 (2013).

14. J. W. Andreasen, E. Makovicky, B. Lebech and S. K. Møller, Phys. Chem. Miner. 35, 447 (2008).

15. T. Barbier; P. Lemoine, S. Gascoin, O. I. Lebedev, A. Kaltzoglou, P. Vaqueiro, A. V. Powell, R. I. Smith and E. Guilmeau, J. Alloys Comp. 634, 253 (2015).

16. R.I. Smith, S. Hull, M.G. Tucker, H.Y. Playford, D.J. McPhail, S.P. Waller, S.T. Norberg and S.G. Eriksson, Rev. Sci. Instrum, submitted (2019).

17. P. Vaqueiro, G. Guélou and A. V. Powell; Liquid-like behaviour of copper in thermoelectric tetrahedrites, STFC ISIS Neutron and Muon Source, 2015, https://doi.org/10.5286/ISIS.E.RB1510166

18. O. Arnold, J. C. Bilheux, J. M. Borreguero, A. Buts, S. I. Campbell, L. Chapon, M. Doucet, N. Draper, R. F. Leal, M. A. Gigg, V. E. Lynch, A. Markvardsen, D. J. Mikkelson, R. L. Mikkelson, R. Miller, K. Palmen, P. Parker, G. Passos, T. G. Perring, P. F. Peterson, S. Ren, M. A. Reuter, A. T. Savici, J. W. Taylor, R. J. Taylor, R. Tolchenoy, W. Zhou, J. Zikoysky, Nucl. Instrum. Methods Phys. Res. 764, 156 (2014).

19. A. C. Larson, R. B. von Dreele, General Structure Analysis System, Los Alamos Laboratory, [Report LAUR 85-748] 1994.

20. A. Pfitzner and S. Reiser, Z. Kristallogr. 217, 51 (2002).

21. H.-S. Kim, Z. M. Gibbs, Y. Tang, H. Wang, and G. J. Snyder, APL Materials 3, 041506 (2015) 
22. H. Wang, S. Bai, L. Chen, A. Cuenat, G. Joshi, H. Kleinke, J. König, H. W. Lee, J.

Martin, M.-W. Oh, W. D. Porter, Z. Ren, J. Salvador, J. Sharp, P. Taylor, A. J. Thompson, Y.

C. Tseng, J. Electron. Mater. 44, 4482 (2015).

23. P. Lemoine, C. Bourgès, T. Barbier, V. Nassif, S. Cordier and E. Guilmeau, J. Solid State Chem. 247, 83 (2017).

24. K. Friese, A. Grzechnik, E. Makovicky, T. Balic-Zunic and S. Karup-Møller, Phys Chem Miner. 35, 455 (2008).

25. B. C. Sales, D. G. Mandrus and B. C. Chakoumakos, Semiconduct. Semimet. 70, 1 (2001).

26. K. Suekuni, K. Tsuruta, M. Kunii, H. Nishiate, E. Nishibori, S. Maki, M. Ohta, A.

Yamamoto, and M. Koyano, J. Appl. Phys. 113, 043712 (2013).

27. J. Li, M. Zhu, D. L. Abernathy, X. Ke, D. T. Morelli, and W. Lai, APL Materials 4, $104811(2016)$

28. P. Vaqueiro, G. Guélou, A. Kaltzoglou, R. I. Smith, T. Barbier, E. Guilmeau and A. V. Powell, Chem. Mater. 29, 4080 (2017).

29. P. Vaqueiro, R. A. R. Al Orabi, S. D. N. Luu, G. Guélou, A. V. Powell, R. I. Smith, J.-P. Song, D. Wee and M. Fornari, Phys. Chem. Chem. Phys. 17, 31735 (2015).

30. W. Lai, Y. Wang, D. T. Morelli, and X. Lu, Adv. Funct. Mater. 25, 3648 (2015).

31. K. Suekuni, C. H. Lee, H. I. Tanaka, E. Nishibori, A. Nakamura, H. Kasai, H. Mori, H. Usui, M. Ochi, T. Hasegawa, M. Nakamura, S. Ohira-Kawamura, T. Kikuchi, K. Kaneko, H. Nishiate, K. Hashikuni, Y. Kosaka, K. Kuroki and T. Takanatake, Adv. Mater. 30, 1706230 (2018).

32. Y. Bouyrie, C. Candolfi, S. Pailhes, M. M. Koza, B. Malaman, A. Dauscher, J. Tobola, O. Boisron, L. Saviot and B. Lenoir, Phys. Chem. Chem. Phys. 17, 19751 (2015).

33. G. Dennler, R. Chmielowski, S. Jacob, F. Capet, P. Roussel, S. Zastrow, K. Nielsch, I. Opahle and G. K. H. Madsen, Adv. Energy Mater. 4, 1301581 (2014). 
34 T. Caillat, J. Kulleck, A. Borshchevsky, and J.P. Fleurial, J. Appl. Phys. 79, 8419 (1996).

35. K.W. Schlichting, N.P. Padture, P.G. Klemens, J. Mater. Sci. 36, 3003 (2001).

36. A. F. May, O. Delaire, J. L. Niedziela, E. Lara-Curzio, M. A. Susner, D. L. Abernathy, M. Kirkham, and M. A. McGuire, Phys. Rev. B 93, 064104 (2016). 


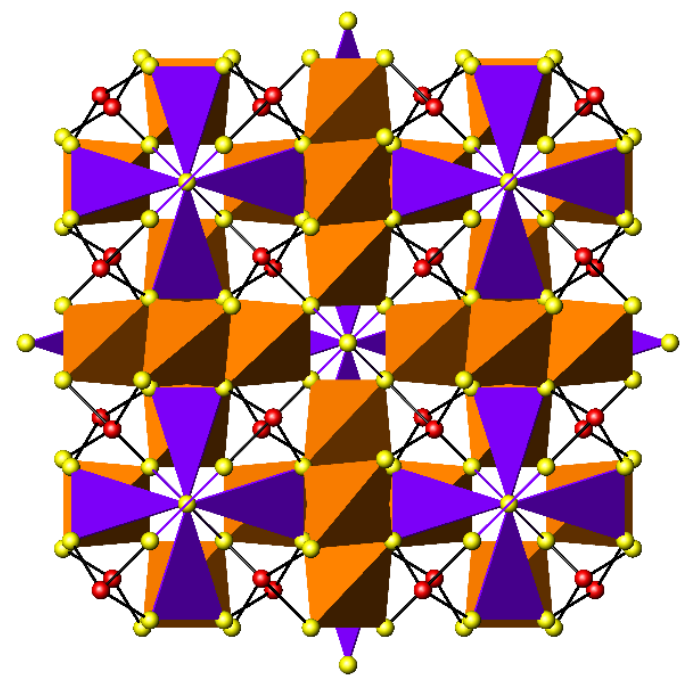

Figure 1. View of the crystal structure of tetrahedrite, with the $\mathrm{CuS}_{4}$ tetrahedra and the $\mathrm{CuS}_{3}$ trigonal planar units shown in orange and purple respectively. Antimony atoms are shown as red circles, and sulfur atoms as yellow circles. 

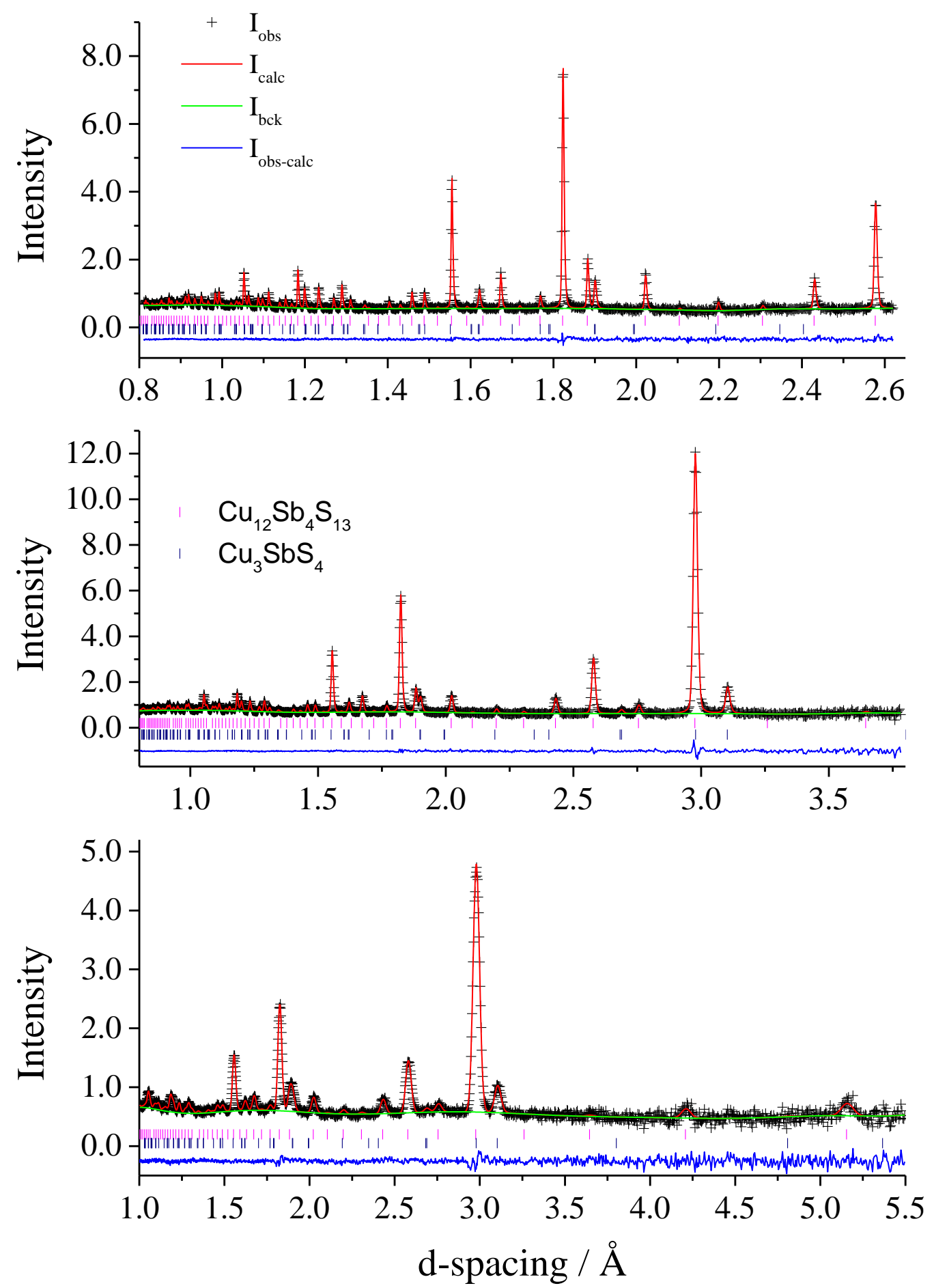

Figure 2. Observed (crosses), calculated (full line) and difference (lower full line) profiles for $\mathrm{Cu}_{12} \mathrm{Sb}_{4} \mathrm{~S}_{13}$ at $313 \mathrm{~K}$ from Rietveld refinements using powder neutron diffraction data collected on the Polaris diffractometer. From top to bottom, bank $5\left(2 \theta=146.72^{\circ}\right)$, bank 4 $\left(2 \theta=92.59^{\circ}\right)$ and bank $3\left(2 \theta=52.21^{\circ}\right)$. Reflection markers for $\mathrm{Cu}_{12} \mathrm{Sb}_{4} \mathrm{~S}_{13}$ (top) and the minority impurity phase, $\mathrm{Cu}_{3} \mathrm{SbS}_{4}$, (bottom) are shown. 

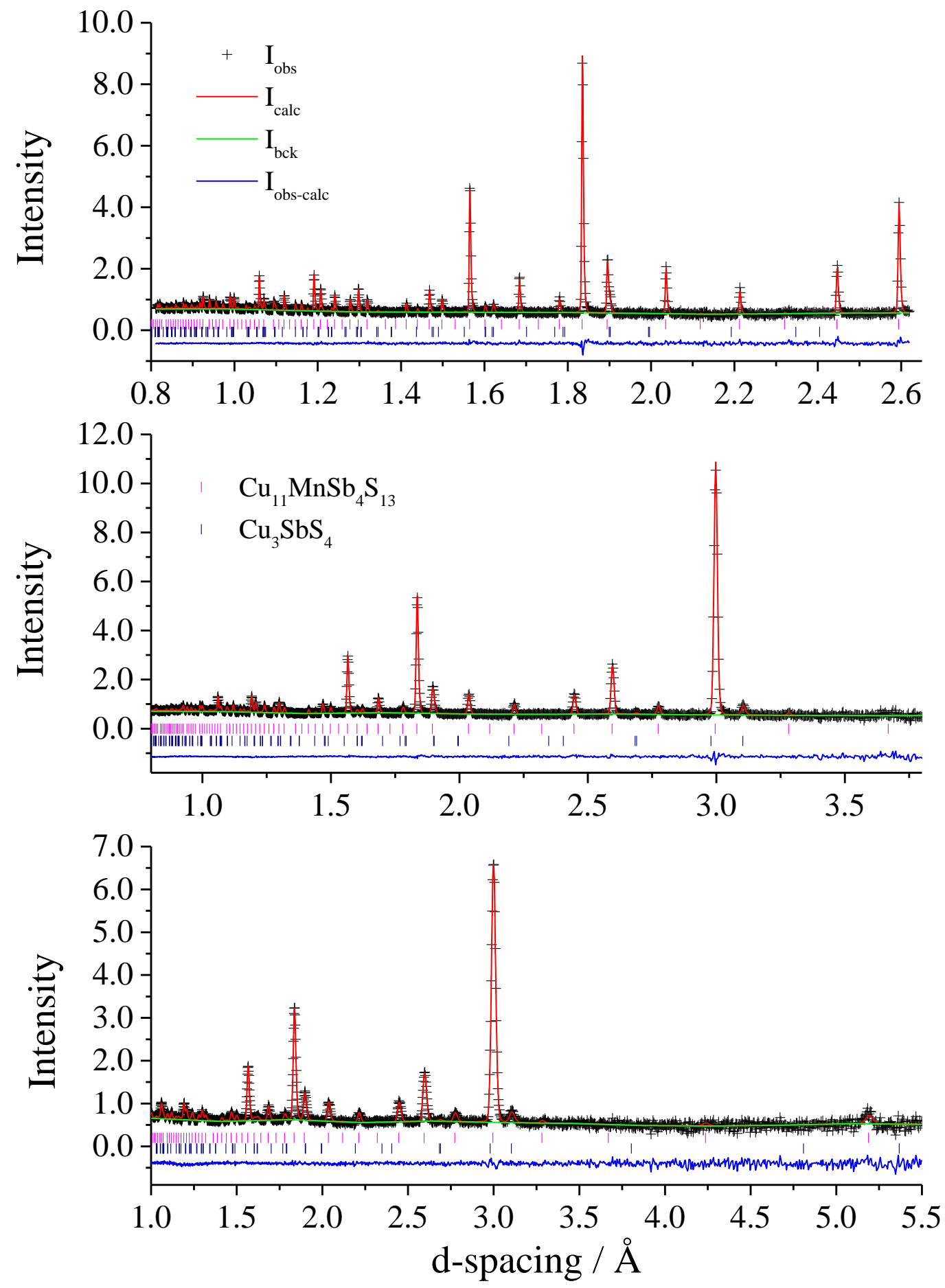

Figure 3. Observed (crosses), calculated (full line) and difference (lower full line) profiles for $\mathrm{Cu}_{11} \mathrm{MnSb}_{4} \mathrm{~S}_{13}$ at $303 \mathrm{~K}$ from Rietveld refinements using powder neutron diffraction data collected on the Polaris diffractometer. From top to bottom, bank $5\left(2 \theta=146.72^{\circ}\right)$, bank 4 $\left(2 \theta=92.59^{\circ}\right)$ and bank $3\left(2 \theta=52.21^{\circ}\right)$. Reflection markers for $\mathrm{Cu}_{11} \mathrm{MnSb}_{4} \mathrm{~S}_{13}$ (top) and the minority impurity phase, $\mathrm{Cu}_{3} \mathrm{SbS}_{4}$, (bottom) are shown. 
(a)

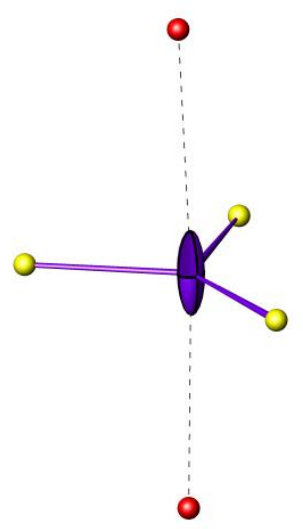

(b)

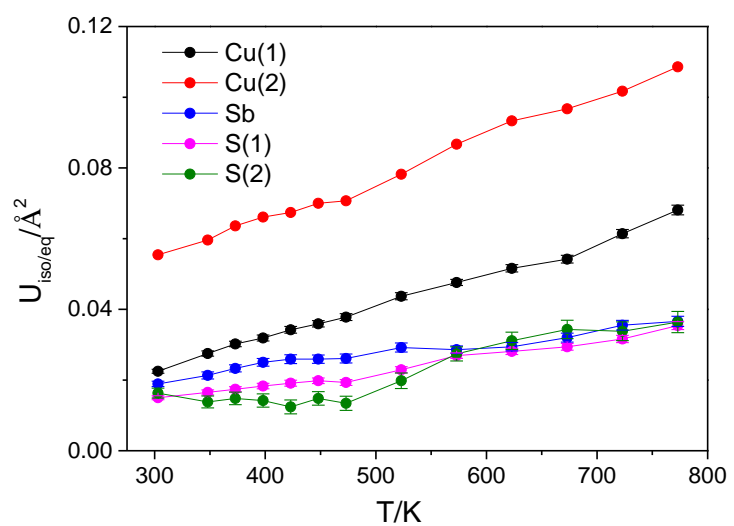

Figure 4. (a) The anisotropic thermal ellipsoid of the $\mathrm{Cu}(2)$ site. $\mathrm{Cu}(2)$ is shown as a purple ellipsoid, antimony as red circles and sulfur as yellow circles. (b) Temperature dependence of the atomic displacement parameters for $\mathrm{Cu}_{11} \mathrm{MnSb}_{4} \mathrm{~S}_{13}$. For $\mathrm{Cu}(2)$, the equivalent $\mathrm{U}_{\text {iso }}$ is plotted. 


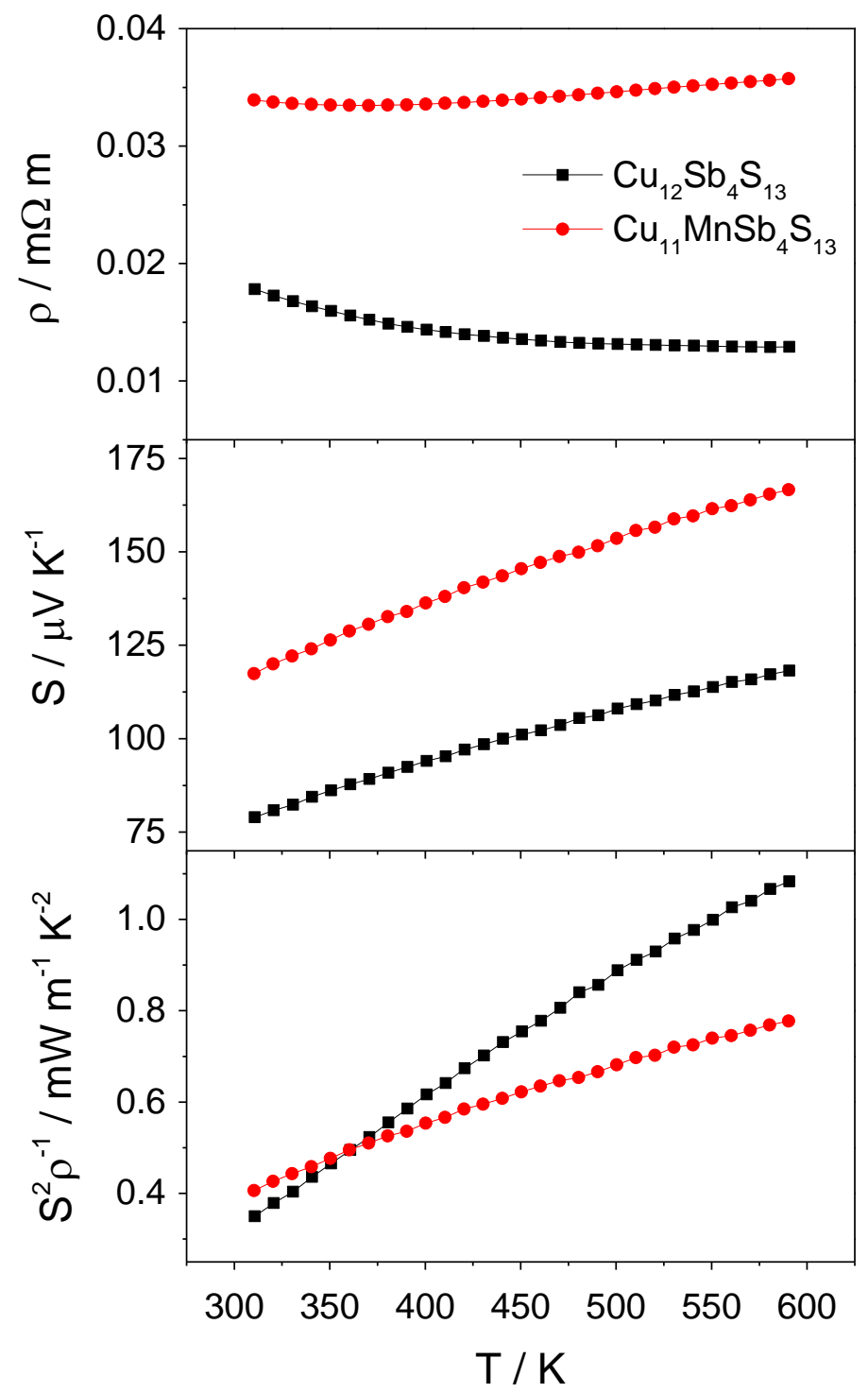

Figure 5 Temperature dependence of the electrical resistivity (top), Seebeck coefficient (middle) and the resulting power factor (bottom) of $\mathrm{Cu}_{12-\mathrm{x}} \mathrm{Mn}_{\mathrm{x}} \mathrm{Sb}_{4} \mathrm{~S}_{13}(\mathrm{x}=0,1)$. 


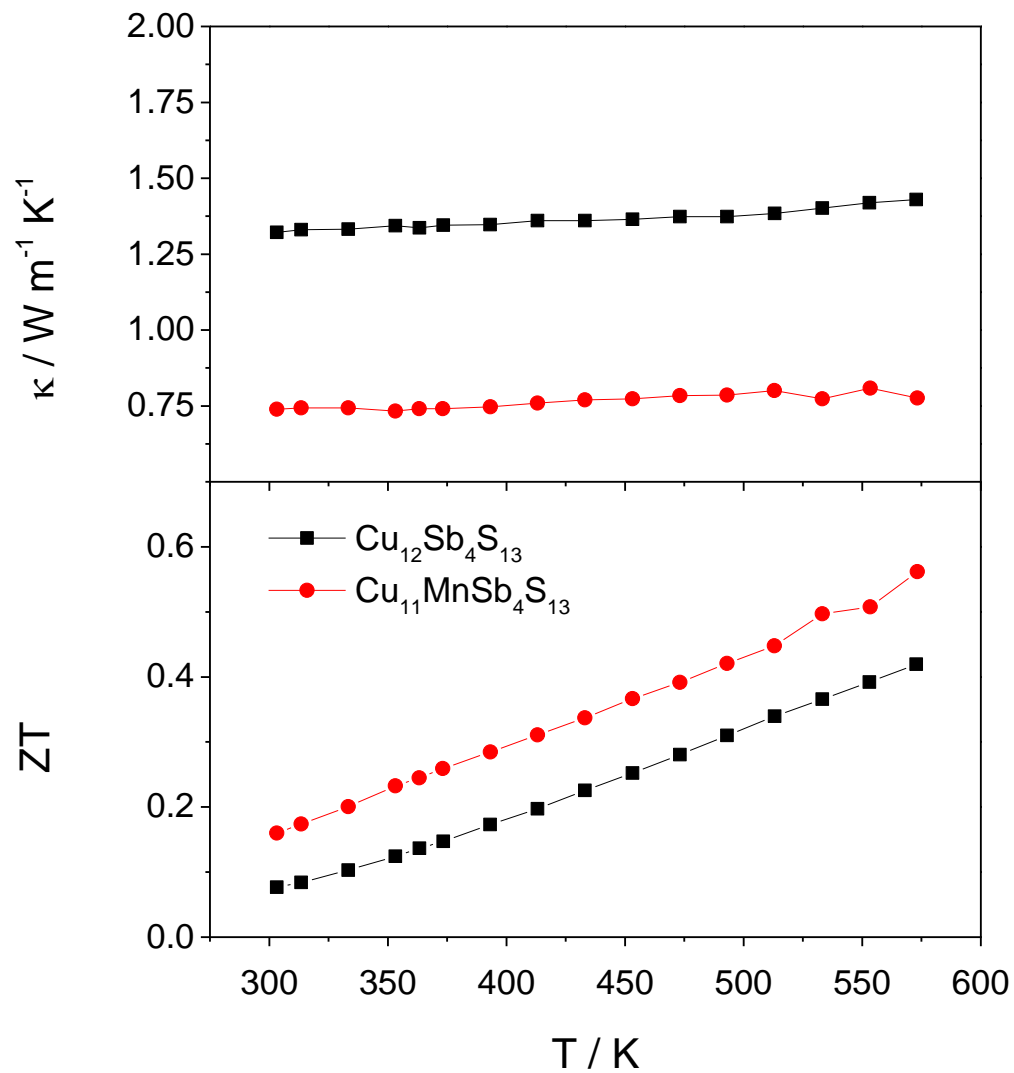

Figure 6. Temperature dependence of the thermal conductivity and the figure of merit, ZT, of $\mathrm{Cu}_{12-\mathrm{x}} \mathrm{Mn}_{\mathrm{x}} \mathrm{Sb}_{4} \mathrm{~S}_{13}(\mathrm{x}=0,1)$. 